\title{
LA DISCIPLINA DEL TRÁFICO AÉREO EN MATERIA DE RUIDO \\ (Comentario a la STS de 13 de octubre de 2008)
}

\author{
ANTONIO FORTES MARTÍN \\ Profesor Titular de Derecho Administrativo \\ Universidad Carlos III de Madrid
}

SUMARIO

I. Tráfico aéreo y contaminación acústica.

II. La seguridad de las personas ante las operaciones de tráfico aéreo: derecho a la vida y a la integridad física.

III. El sobrevuelo de aeronaves y el derecho a la vida privada y familiar en el ámbito domiciliario: umbrales de ruido soportables y condiciones mínimas de habitabilidad en las viviendas.

IV. Conclusiones.

\section{TRÁFICO AÉREO Y CONTAMINACIÓN ACÚSTICA}

El desarrollo de la aviación civil a partir del siglo xx y la aparición de la aeronave como instrumento gracias al cual se puede posibilitar la navegación ${ }^{1}$, y con ella el movimiento en la atmósfera, ha generado una serie de problemas jurídicos inéditos hasta el momento que el Derecho se ve impelido a atajar en aras de la salvaguarda de la integridad, fundamentalmente, de bienes y

1 La aeronáutica es navegación, pero también lo es circulación, es en definitiva movimiento, porque de nada sirve la potencialidad de la navegación sino lo es puesta al servicio de un tráfico ulterior. En este sentido, el artículo 11 regla $5^{\circ}$ de la Ley penal y procesal de la navegación aérea de 24 de diciembre de 1964 dispone claramente que "la navegación aérea comienza en el momento en que una aeronave se pone en movimiento con su propia fuerza motriz para emprender el vuelo y termina cuando, realizado el aterrizaje, queda aquélla inmovilizada y son parados sus motores". 
personas. Surge así un corpus iuris que condiciona la forma de realizar, de manera ordenada y segura, el tráfico aéreo².

Las operaciones de tráfico aéreo, por lo que aquí ahora nos interesa, también conllevan una serie de efectos para el medio ambiente y la salud de las personas, principalmente en forma de emisiones contaminantes y acústicas. El ruido es indisociable a las operaciones de tráfico aéreo, sobre todo porque el ruido resulta del empuje de las aeronaves, necesario por otra parte para la sustentación de las mismas. Es por ello que tráfico aéreo y contaminación acústica constituyen las dos variables de una intrincada relación asociativa con difíciles visos de solución. Empero, esa solución se ha tratado de propiciar a través de un complejo normativo aeronáutico, tanto en el plano interno estatal, como en el comunitario europeo ${ }^{3}$. Centrándonos ahora en la perspectiva interna estatal, el problema de la contaminación acústica generado por las operaciones de tráfico aéreo ha tratado de solventarse desde una doble vertiente, a saber, dinámica y estática. La primera de ellas, la que damos en denominar dinámica, se refiere al propio movimiento y circulación de aeronaves. De este modo, el artículo 144 de la Ley de navegación aérea expresamente dispone que "las disposiciones sobre policía de la circulación aérea y disciplina de vuelo obligan a todas las aeronaves civiles o militares, sin distinción de categoría o clase". Esas disposiciones de policía de circulación aérea o disciplina de vuelo, en lo que aquí ahora más nos interesa, pasan por la aprobación de Circulares aeronáuticas en las que se fijan los procedimientos de disciplina de tráfico aéreo en materia de ruido. Unos procedimientos de disciplina a los que quedan obligadas todas las aeronaves civiles, en los términos dispuestos por el artículo 87 de la Ley 50/98, de 30 de diciembre, de medidas fiscales, administrativas y del orden social ${ }^{4}$, tanto en las fases de despegue y ascenso, como en las de aproximación y aterrizaje en los

2 La llamada disciplina de vuelo o del "buen orden del aire" conforme se establece en la Ley 48/60, de 21 de julio, de navegación aérea en su capítulo XVII, que precisamente lleva por título "De la policía de la circulación aérea". En este sentido, el artículo 142 de la Ley de navegación aérea dispone que "la policía de la circulación aérea abarcará el cumplimiento de cuantos Reglamentos, disposiciones y normas permanentes o eventuales tiendan a conseguir una rápida, ordenada y segura circulación de las aeronaves, tanto en vuelo como en tierra".

3 Resulta imposible, por el carácter limitado de este trabajo, dar cuenta de la ingente producción normativa comunitario-europea en materia de ruidos generados por el tráfico aéreo. No obstante queremos dar cuenta, si cabe, de las más importantes disposiciones en la materia. Así, la Directiva 89/629, de 4 de diciembre, de limitación de emisiones sonoras de los aviones de reacción subsónicos civiles; la Directiva 92/14, de 2 de marzo, relativa a la limitación del uso de aviones objeto del Anexo 16 del Convenio relativo a la aviación civil internacional y que tiene por objeto regular determinadas restricciones a la utilización de aviones de reacción subsónicos civiles encaminadas a la limitación de las emisiones sonoras; la Comunicación de la Comisión "Transporte aéreo, medio ambiente y retos del desarrollo sostenible". COM (99) 640, de 1 de diciembre; y la Directiva 2002/30, de 26 de marzo, de establecimiento de normas y procedimientos para la introducción de restricciones operativas relacionadas con el ruido en los aeropuertos comunitarios.

4 En la redacción dada a ese mismo precepto por la Disposición Adicional Tercera de la Ley 21/2003, de 7 de julio, de seguridad aérea. 
aeropuertos. Estos procedimientos de disciplina de tráfico aéreo en materia de ruido $^{5}$ se aprueban específicamente para cada aeropuerto ${ }^{6}$ teniendo en cuenta para ello los elementos con trascendencia acústica, las características físicas y de configuración del aeropuerto en cuestión, los sistemas de ayudas a la navegación, y las características y limitaciones de los aviones afectados. Y mediante los mismos, en los términos dispuestos por el artículo 87.3 de la Ley 50/98, de 30 de diciembre, pueden determinarse, entre otros extremos, las restricciones de uso de las distintas rutas establecidas de aproximación en función de las características y equipamiento de las aeronaves; las restricciones de sobrevuelo o de altitud en zonas de especial sensibilidad acústica; los niveles máximos de ruido establecidos en puntos de las trayectorias o cercanos al aeropuerto; y las desviaciones máximas permitidas respecto de las rutas definidas para cada maniobra, incluyendo las alturas a partir de las cuales se pueden permitir desviaciones mayores.

Por lo que se refiere, en segundo término, a la segunda de las vertientes o perspectivas que hemos delimitado con anterioridad, la dimensión estática, la misma responde a la incidencia que un aeropuerto y el resto de las infraestructuras aeroportuarias presentan en el ámbito territorial circundante en el que se sitúan. De todas esas eventuales incidencias destacan las afecciones acústicas, por su repercusión en el planeamiento territorial y urbanístico, y que se concretan a través de los planos o mapas de ruido en los que quedan representados las curvas isófonas - comúnmente conocidas como "huellas de ruido" - correspondientes a determinados niveles de inmisión acústica de acuerdo con las condiciones expresadas en el correspondiente Plan Director del Aeropuerto ${ }^{7}$. La gestión del aeropuerto debe tender, de esta forma, a minorar progresivamente el impacto de los ruidos producidos por los despegues y aterrizajes de las aeronaves a través de un sistema de monitorización

5 Los procedimientos se aprueban por el Ministerio de Fomento y se contienen en las AIP (Publicaciones de información aeronáutica), los NOTAM (Notification to airmen) y las AIC (Circulares de información aeronáutica), como manifestaciones de actos de comunicación de información aeronáutica a los que se refiere el Libro octavo "Servicio de información aeronáutica" del Reglamento de circulación aérea (RD 57/2002, de 18 de enero). Todo ello sobre la base del marco normativo dispuesto por el capítulo IV de la Ley 48/60, de 21 de julio, de navegación aérea, el artículo 87 de la Ley 50/98, de 30 de diciembre, de medidas fiscales, administrativas y del orden social, y del RD 1257/2003, de 3 de octubre, por el que se regulan los procedimientos para la introducción de restricciones operativas relacionadas con el ruido de los aeropuertos a través de medidas relacionadas con el ruido que limitan o reducen el acceso de aviones de reacción subsónicos civiles a un aeropuerto.

6 En concreto, por lo que se refiere a los dos principales aeropuertos de nuestro país vid. Circular 1/2006, de 23 de mayo, de la Dirección General de Aviación Civil (DGAC), por la que se establecen procedimientos de disciplina de tráfico aéreo en materia de ruido en el aeropuerto de Barcelona, y Circular 2/2006, de 26 de julio, de la DGAC, por la que se establecen procedimientos de disciplina de tráfico aéreo en materia de ruido en el aeropuerto de Madrid-Barajas.

7 Vid. RD 2591/98, de 4 de diciembre, de ordenación de los aeropuertos de interés general y su zona de servicio en ejecución de lo dispuesto por el artículo 166 de la Ley 13/96, de 30 de diciembre. Vid. también Orden FOM/926/2005, de 21 de marzo, por la que se regula la revisión de las huellas de ruido de los aeropuertos de interés general. 
de ruidos y sendas de vuelo que eviten en lo posible las grandes zonas edificadas ${ }^{8}$.

Así las cosas y sobre la base de los anteriores antecedentes, merece ahora nuestra atención valorar el alcance actual de la llamada disciplina del tráfico aéreo en materia de ruido, sobre todo a raíz de la eventual incidencia que el sobrevuelo a baja altura de aviones puede provocar en los derechos fundamentales a la vida e integridad física y moral (artículo $15 \mathrm{CE}$ ), a la intimidad personal y familiar (artículo 18.1 CE) y a la inviolabilidad del domicilio (artículo 18.2 CE). Para ello resulta revelador el pronunciamiento del Tribunal Supremo (TS) de 13 de octubre de $2008^{9}$ con ocasión, precisamente, de la incidencia del ruido causado por el sobrevuelo de los aviones sobre la urbanización "Ciudad Santo Domingo" (en adelante la urbanización), del municipio madrileño de Algete, como consecuencia de las maniobras diurnas de aproximación en vistas al aterrizaje en la pista 18R/36L $\left(18 \mathrm{R}^{10}\right)$ del aeropuerto de Barajas en los días en que éste opera en configuración sur ${ }^{11}$.

Centrándose la problemática que vamos a analizar en el aeropuerto de Madrid-Barajas, interesa dar cuenta que el principal aeropuerto del país es un aeropuerto de interés general del Estado al amparo de lo dispuesto en el ar-

8 La Comisión de Seguimiento de las Obras de Ampliación del Aeropuerto de Madrid (CSAM) — creada por la Resolución de 30 de noviembre de 2001, de la Secretaría General de Medio Ambiente, por la que se formula Declaración de Impacto Ambiental (en adelante DIA) del proyecto de ampliación del sistema aeroportuario de Madrid (BOE núm 298, de 13 de diciembre de 2004) en sustitución de la hasta entonces Comisión de Vigilancia del Ruido- acordó el 28 de enero de 2004 las huellas de ruido asociadas al conjunto de maniobras y rutas de salida y entrada al aeropuerto de Barajas, que incorpora el esquema de utilización operativa de las pistas de vuelo y las rutas asociadas con el fin de minimizar el impacto acústico sobre el entorno.

9 Sentencia del Tribunal Supremo de la Sala de lo contencioso-administrativo, Sección Séptima (Ponente: Excmo Sr. D. Pablo Lucas Murillo de la Cueva) en el recurso de casación n. ${ }^{\circ}$ 1553/2006 contra la Sentencia de 31 de enero de 2006 (RJCA 2007/184) del Tribunal Superior de Justicia de Madrid (Sala de lo contencioso-administrativo, Sección Novena) dictada a su vez en el recurso contencioso-administrativo n. ${ }^{\circ} 109 / 2004$ tramitado como procedimiento especial para la protección de los derechos fundamentales —artículos 114 a 122 de la Ley 29/98, de 13 de julio, reguladora de la Jurisdicción contencioso-administrativa (LJCA)—, sobre situación de vía de hecho producida por la DGAC del Ministerio de Fomento y el Ente Público Aeropuertos Españoles y Navegación Aérea (AENA).

10 La pista 18R/36L, situada a unos dieciocho kilómetros de la urbanización, tiene unas dimensiones de 4.440 metros de longitud por 60 metros de anchura. La apertura al tráfico aéreo civil de esta pista (la tercera por aquél entonces en el aeropuerto de Barajas) fue autorizada por Resolución de la DGAC de 4 de noviembre de 1998. Fruto de las obras de ampliación del aeropuerto de Barajas, por Resolución de 10 de abril de 1996 de la Dirección General de Información y Evaluación Ambiental del por entonces Ministerio de Obras Públicas, Transportes y Medio Ambiente, se formuló DIA del proyecto de ampliación del aeropuerto de Barajas que contemplaba, precisamente, la ampliación del campo de vuelo del aeropuerto mediante la entrada en funcionamiento de la nueva pista 18R (BOE núm 89, de 12 de abril de 1996).

11 Según el anexo I "Condiciones de uso de pistas y trayectorias" de la Circular 2/2006, de 26 de julio, de la DGAC por la que se establecen procedimientos de disciplina de tráfico aéreo en materia de ruido en el aeropuerto de Madrid-Barajas, las pistas preferentes en configuración sur durante el día (de 7 a 23 horas) y en condiciones normales de operación (superficie de la pista seca o mojada pero con buena acción de frenado) son las pistas 18L/18R 
tículo 149.1.20 CE y del RD 2858/81, de 27 de noviembre, sobre calificación de aeropuertos civiles, reconocido también como aeropuerto civil internacional con categoría OACI (Organización de Aviación Civil Internacional) "4-E" abierto al tráfico aéreo las veinticuatro horas del día. La localización física del aeropuerto, rodeado de áreas urbanas densamente pobladas en las que la incidencia del ruido producido por los aviones afecta a la calidad de vida de sus habitantes sumado a la intensidad del tráfico aéreo que soporta, obligó en el año 1992, en el seno del llamado "Plan Barajas", a la ampliación de las instalaciones existentes y, por lo que nos interesa a los efectos de este trabajo, a la construcción de una nueva pista 18R-36L, dada la inviabilidad de la construcción de un nuevo aeropuerto ${ }^{12}$

No cabe duda alguna que definir las trayectorias de vuelo más óptimas y recomendables a seguir por parte de las aeronaves en sus operaciones de aproximación a un aeropuerto para tomar tierra forma parte del ejercicio de una serie de potestades de disciplina del vuelo con una destacada particularidad por lo que a su eventual impacto acústico se refiere. Esa particularidad no es otra que la concentración de amplias dosis de discrecionalidad en la Administración, ya que la norma no puede prefigurar en su plenitud las condiciones de ejercicio del control del tráfico ${ }^{13}$ de una forma válida para cada lugar y momento. De esta manera, la Administración cuenta con un margen de apreciación valorativo para determinar en cada caso lo que conviene al interés público, esto es, la Administración decide en cada momento - motivos de oportunidad y conveniencia-, las distancias que deben respetar las aeronaves entre sí, la cota de altura y los niveles de vuelo, la dirección a seguir, los virajes, la preferencia en el paso en los cruces de aeronaves, las restricciones o alteraciones de vuelo por determinadas zonas, e incluso la velocidad y trayectoria de aproximación a un aeropuerto, todo para garantizar unas operaciones aéreas seguras y ordenadas. La seguridad es por tanto el valor fundante en el que se sustenta el conjunto de las operaciones de tráfico aéreo ${ }^{14}$. Con esto se justifica que a la hora de posibilitar la aproximación de las aeronaves a los aeropuertos, lo importante no sea otra cosa que garantizar el aterrizaje en las mejores condiciones posibles de seguridad, valorando fundamentalmente la velocidad ascencional y vertical de descenso, y sólo cuando sea apropiado y en la medida de lo posible, la toma en consideración de procedimientos para la atenuación del ruido generado por las maniobras de aterri-

12 Vid. Orden del Ministerio de Fomento de 19 de noviembre de 1999 por la que se aprueba el Plan Director del Aeropuerto de Madrid-Barajas.

13 Buena prueba de ello lo determina el Apéndice G epígrafe 3.2.2 del Reglamento de la circulación aérea. Así, a la hora de determinar las distintas trayectorias de vuelo, entre los factores que necesariamente han de tenerse en cuenta, constan, entre otros, el número de pistas a utilizar, la dirección de utilización de las pistas (en configuración norte o sur), o la disposición y localización de las ayudas para el aterrizaje de las aeronaves.

14 En este sentido, y como se reconoce en el apartado V de la Exposición de Motivos de la Ley de seguridad aérea, "el constante incremento que el tráfico aéreo ha experimentado en las últimas décadas genera necesidades crecientes de seguridad". 
zaje y despegue ${ }^{15}$. De esta forma, y en la tensión seguridad-protección ambiental, la seguridad parece erigirse como un valor prioritario e irrenunciable en los procedimientos de disciplina de tráfico aéreo en materia de ruido. Así se desprende, en el caso del aeropuerto de Madrid-Barajas, de los artículos 1 y 3 de la Circular 2/2006, de 26 de julio, de la DGAC, que imponen a los operadores aéreos, pilotos y controladores aéreos seguir el régimen de utilización de pistas, trayectorias de vuelo, y el empleo de procedimientos de atenuación del ruido para el despegue y el aterrizaje indicados en el anexo I de la Circular citada, salvo por razones de seguridad ${ }^{16}$.

\section{LA SEGURIDAD DE LAS PERSONAS ANTE LAS OPERACIONES DE TRÁFICO AÉREO: DERECHO A LA VIDA Y A LA INTEGRIDAD FÍSICA}

Los demandantes en casación planteaban ya en la instancia la vulneración del derecho a la vida como consecuencia del incesante sobrevuelo de aeronaves a baja altura de sus viviendas, y ello a raíz, tanto del peligro que entrañaría un eventual accidente, como por el vertido o pérdida de carga de combustible - queroseno- de los aviones en las operaciones de aproximación al aeropuerto para tomar tierra. Es por ello que el TS, a partir de la incongruencia omisiva, por falta de pronunciamiento del TSJ de Madrid a la pretensión planteada por los trescientos cuarenta y seis recurrentes, considera en la Sentencia objeto de este comentario que pese a las escasas precisiones contenidas en los escritos de demanda, las manifestaciones de los actores, sobre todo las expresadas en sus escritos de conclusiones, "tienen autonomía bastante para constituir una pretensión distinta de las relacionadas con la protección de su integridad física y moral y con la llamada intimidad domiciliaria". El máximo órgano jurisdiccional anula por ende la Sentencia de la instancia y entra a resolver el recurso contencioso-administrativo inicialmente planteado, si bien con distinto éxito en relación con las diferentes pretensiones ejercidas por los actores.

En efecto, la estimación del recurso es sólo parcial en la medida en que el TS, entendiendo que han de prosperar las tesis de los recurrentes sobre la vulneración del derecho a la intimidad domiciliaria en los términos que po-

15 Así, por ejemplo, a raíz del accidente del vuelo CRX 3597 el 24 de noviembre de 2001, en el que un avión se estrelló en la aproximación al aeropuerto de Zurich causando la muerte de veinticuatro personas, el Informe de la Comisión suiza de investigación de accidentes advirtió que la aeronave había sido autorizada a una aproximación a la pista 28 por motivos de reparto de cuota ambiental de ruido, cuando también estaba disponible en esos momentos la pista 14, que contaba con mejores sistemas de ayudas a la navegación que la pista 28. Desde entonces, muchas de las Agencias de seguridad aérea hoy día existentes han comenzado a cuestionar el carácter acertado de anteponer criterios puramente ambientales a los de seguridad en las operaciones de aproximación y aterrizaje.

16 Aparte de también por razones meteorológicas, de inoperatividad de alguna pista o de algún equipo terrestre de ayuda a la navegación aérea que inutilice algunas de las salidas y llegadas normalizadas. 
drán comprobarse en el siguiente epígrafe, decide por el contrario no acoger las pretensiones fundadas en la lesión de los derechos a la vida y a la integridad física y moral.

Por lo que se refiere en primer lugar al derecho a la vida y al peligro de accidente que puede ocasionar el sobrevuelo de aeronaves como consecuencia del propio tráfico aéreo y de la presencia de aviones a baja altura en la maniobra de aproximación, con la eventual pérdida o descarga de queroseno, el TS, en el fundamento jurídico octavo de la Sentencia que venimos comentando, advierte que, pese al elevado número de operaciones aéreas que tienen lugar sobre la urbanización cuando el aeropuerto de Barajas opera en configuración sur, no hay posibilidad de reconocer o admitir la afección del derecho demandado. Primero porque entiende el máximo órgano jurisdiccional que no hay amenaza a la vida de los residentes dado que en ningún momento se ha acreditado que los posibles vertidos o pérdidas de queroseno o incluso la contaminación derivada de los escapes de los motores haya alcanzado unos niveles de concentración en la zona residencial de los demandantes capaces de afectar su vida e integridad física. Y, en segundo lugar, porque en lo que se refiere al eventual acaecimiento de un accidente, la mera posibilidad $^{17}$ no puede implicar una vulneración del derecho a la vida reconocido en el artículo 15 CE.

Resulta un hecho incontestable que la circulación de una aeronave, estando ésta próxima a un aeropuerto para tomar tierra, puede entrañar un peligro no sólo para los propios ocupantes — pasajeros y personal de vuelosino también para los habitantes de las zonas próximas ante el eventual acaecimiento de un siniestro que suponga el precipitado de la aeronave. Con esta innegable realidad, fácilmente se colige que la policía administrativa de la circulación aérea surge a raíz de las primeras manifestaciones de la capacidad del hombre para elevarse sobre la superficie de la tierra. Así, resulta de forma recurrente puesto de relieve por todos los estudiosos en la materia que ya en el año 1784 Lenoir - Prefecto general de policía de París - dictase una ordenanza que prohibía, sin contar con la preceptiva autorización, las ascensiones en globo. Esta medida de policía trataba de poner freno a una práctica que, mediante algunos episodios aislados — como el de los hermanos Montgolfier un año antes ${ }^{18}$ — ya habían tenido lugar en la ciudad francesa.

Esta disposición reglamentaria dictada por el Prefecto general de policía ha pasado a la historia como la primera norma jurídica que, bajo el régimen de policía administrativa, regula la actividad aeronáutica propiamente dicha. Pero lo más importante ahora a nuestros efectos, la ordenanza trataba de proteger sobre todo la integridad y por supuesto también la vida de las personas

17 Téngase en cuenta que entre las alegaciones presentadas al proyecto de ampliación del aeropuerto de Barajas, una de las constantes más repetidas era la ausencia en el proyecto de un análisis de riesgo de los movimientos de aeronaves en la fase de sobrevuelo de poblaciones. Vid. Anexo I de la DIA de 1996.

$18 \mathrm{El}$ primer vuelo tripulado en globo, creado por los hermanos Montgolfier y autorizado por Luis XVI, tuvo lugar en Francia el 21 de noviembre de 1783. 
en la superficie que veían cómo sobre sus cabezas se elevaban, para emprender el vuelo, globos y otra serie de artefactos.

Así las cosas, la conquista del aire por parte del hombre ha entrañado, desde entonces, un riesgo que socialmente admitimos o toleramos dadas las ventajas que, por supuesto y entre otras, ofrece el desplazamiento a larga distancia de personas y cosas utilizando el medio de transporte aéreo. Es justo esta realidad la que interioriza el TS al afirmar que "la existencia de factores de riesgo no la produce por sí misma" [se refiere a la vulneración del derecho a la vida del artículo $15 \mathrm{CE}$, porque de lo contrario quedaría imposibilitado en la práctica el desarrollo de cualquier tipo de actividad que entrañara algún grado de peligro para la vida de las personas. El riesgo, como hemos apuntado, se acepta o se admite en la medida, por supuesto, que se presupone, dada la estricta aplicación de regulaciones administrativas en materia de seguridad aérea, que sólo actúan los operadores aéreos "que satisfacen, entre otros y sobre todo, los requisitos de seguridad imprescindibles para conjurar los riesgos de manera que deje de ser relevante la posibilidad de que se traduzcan en lesión del derecho a la vida". Por todo ello, en la medida en que no hay base alguna para llegar a pensar que la seguridad de todas y cada una de las aeronaves que sobrevuelan la urbanización no está, a priori, garantizada, resulta inviable que el recurso prospere en lo que atañe a la vulneración del derecho a la vida de los residentes.

De otro lado y por lo que se refiere en segundo lugar a la lesión del derecho a la integridad física y moral, la Sentencia en la instancia del TSJ de Madrid de fecha 31 de enero de 2006 (RJCA 2007/184) e impugnada en casación ante el TS, desestimó el recurso al considerar que el nivel de ruido causado por los aviones no tenía la frecuencia, duración e intensidad necesarias para atribuirle la lesión de los derechos tanto a la integridad física como de la intimidad domiciliaria. Esto mismo es lo que también concluye, únicamente en lo que respecta ahora al derecho a la integridad física y moral, el TS en el fundamento jurídico séptimo de la Sentencia de 13 de octubre de 2008.

Interesa constatar, lo primero de todo, que el derecho fundamental a la integridad física y moral tiene una sustantividad propia pese a estar incluido en el mismo precepto - artículo 15 CE- que el derecho a la vida. Es más, su ámbito constitucionalmente garantizado, como ha tenido ocasión de precisar el Tribunal Constitucional (TC) ${ }^{19}$, protege "la inviolabilidad de la persona, no sólo contra ataques dirigidos a lesionar su cuerpo o espíritu, sino también contra toda clase de intervención en esos bienes que carezca del consentimiento de su titular". A mayor abundamiento, el derecho a la integridad física destinado en última instancia a proteger la «incolumidad corporal", en palabras del propio $\mathrm{TC}^{20}$, adquiere una dimensión positiva en relación con el libre de-

19 Vid. SsTC 120/90, de 27 de junio, 215/94, de 14 de julio, 35/96, de 11 de marzo, 207/96, de 15 de diciembre, 119/2001, de 24 de mayo, 220/2005, de 12 de septiembre, y $62 / 2007$, de 27 de marzo.

20 Esto es, el derecho a no sufrir lesión o menoscabo en el cuerpo o en la apariencia externa sin consentimiento de la persona. Vid. STC 207/96, de 16 de diciembre. 
sarrollo de la personalidad "razón por la que se hace imprescindible asegurar su protección no sólo frente a las injerencias ya mencionadas, sino también frente a los riesgos que puedan surgir en una sociedad tecnológicamente avanzada ${ }^{21}$ ", como es éste el caso que nos ocupa con los riesgos que comporta el tráfico y el sobrevuelo de aeronaves como comprobaremos más adelante.

El derecho a la integridad personal, que puede verse lesionado no sólo por acciones sino también por omisiones de los poderes públicos, incorpora, al entenderse comprendido en el $\mathrm{mismo}^{22}$, el derecho a que no se dañe o perjudique la salud de las personas, "si bien no todo supuesto de riesgo o daño para la salud implica una vulneración del derecho fundamental del artículo 15 $\mathrm{CE}$, sino tan sólo aquél que genera un peligro grave y cierto para la misma ${ }^{23}$ ". Precisamente esta entidad del riesgo ${ }^{24}$, en el caso que nos ocupa, es la que conduce al TS a rechazar la pretensión de los recurrentes como consecuencia de la falta de aportación al proceso de prueba suficiente "de que alguno de los actores haya padecido trastornos en su salud que hayan comprometido su integridad física o moral". Porque, en línea con la doctrina constitucional que venimos considerando ${ }^{25}$, si admitimos que no todo supuesto de riesgo o daño para la salud implica una vulneración del artículo $15 \mathrm{CE}$, "Cuando los niveles de saturación acústica que deba soportar una persona, a consecuencia de una acción u omisión de los poderes públicos, rebasen el umbral a partir del cual se ponga en peligro grave e inmediato la salud, podrá quedar afectado el derecho garantizado en el artículo 15 CE".

De la necesidad de acreditar que la exposición continuada a unos niveles intensos de ruido ha puesto en peligro grave e inmediato la salud a los efectos de tener por lesionado el artículo $15 \mathrm{CE}^{26}$, resulta pertinente tener en cuenta que rige en el proceso contencioso-administrativo el principio general -inferido del derogado artículo 1214 del Código Civil y en la actualidad expresado en el artículo 217 de la Ley de Enjuiciamiento Civil- que atribuye la carga de la prueba a aquél que sostiene el hecho - semper necesitas pro-

21 Vid. STC 119/2001, de 24 de mayo y STC 16/2004, de 23 de febrero.

22 Vid. STC 35/96, de 11 de marzo. De forma clara en la STC 5/2002, de 14 de enero, se declara abiertamente que uel derecho a que no se dañe o perjudique la salud personal queda comprendido en el derecho a la integridad personal del artículo 15 CE".

23 Vid. SsTC 119/2001, de 24 de mayo, 5/2002, de 14 de enero, 16/2004, de 23 de febrero, 220/2005, de 12 de septiembre, y 62/2007, de 27 de marzo.

24 Tiene reconocido el máximo intérprete constitucional que la declaración de la lesión del derecho fundamental a la integridad física que se pueda inferir del riesgo relevante "sólo podrá ser efectuada en esta sede cuando resulte palmaria y manifiesta, pues la relevancia del peligro debe apreciarse con inmediación" (STC 220/2005, de 12 de septiembre).

25 Principalmente SsTC 119/2001, de 24 de mayo, y 16/2004, de 23 de febrero.

26 Téngase en cuenta que para que la afectación de la salud de una persona por una determinada actuación de los poderes públicos suponga la lesión de su derecho fundamental a la integridad física es requisito necesario que como consecuencia de aquélla se ponga en peligro grave e inmediato la salud (STC 119/2001, de 24 de mayo) o se produzca lo que la STC 220/2005, de 12 de septiembre ha dado en llamar "un riesgo relevante" que genere un peligro grave y cierto para la salud del afectado. 
bando incumbit illi qui agit - así como los principios consecuentes recogidos en los brocardos que atribuyen la carga de la prueba a la parte que afirma - ei incumbit probatio qui dicit-.

Los recurrentes, a juicio del TS, no han levantado, así pues, la carga de la prueba que sobre ellos pesa, tal y como en su momento apreciara también el TSJ de Madrid, por lo que en modo alguno se ha llegado a probar, más allá de la aportación documental de un informe médico que el Tribunal califica de genérico e indeterminado, ni la existencia de un daño grave e inmediato en la salud de los recurrentes a raíz de los niveles de ruido a los que están expuestos, como tampoco, al no producirse de manera efectiva ese daño, que la situación que padecen pueda de hecho propiciar "un riesgo constatado de producción cierta o potencial pero justificado ad casum, de la causación de un perjuicio para la salud (...), es decir, cuando se generara un riesgo o peligro grave para la salud del afectado ${ }^{27}$.

El umbral definido por el TS de causación de un daño cierto, o del riesgo relevante de que llegue a producirse, impide reconocer la afección del derecho a la integridad física ${ }^{28}$, y ello por la evidente falta de prueba en el caso que nos ocupa en línea con la doctrina sentada por el TC. Una doctrina, a día de hoy, y pese a lo expuesto, según la cual la vulneración del artículo 15 CE en lo que se refiere al derecho a la integridad física o moral no pasa porque "la lesión de la integridad se haya consumado, lo que convertiría la tutela constitucional en una protección ineficaz ex post, bastando por el contrario que se acredite un riesgo relevante de que la lesión pueda llegar a producirse ${ }^{29}$.

\section{EL SOBREVUELO DE AERONAVES Y EL DERECHO A LA VIDA PRIVADA Y FAMILIAR EN EL ÁMBITO DOMICILIARIO: UMBRALES DE RUIDO SOPORTABLES Y CONDICIONES MÍNIMAS DE HABITABILIDAD EN LAS VIVIENDAS}

El derecho a la vida y a la integridad física y personal no parecen, a juicio del TS, que puedan lesionarse por el mero sobrevuelo de aviones en sus necesarias maniobras de aproximación a un aeropuerto para tomar tierra. Por el

27 Vid. STC 62/2007, de 27 de marzo.

28 Es más, como con anterioridad ha precisado el propio TS en la Sentencia de 10 de abril de 2003 (RJ 2003/4920), tampoco los ruidos pueden llegar a ser constitutivos de torturas en la acepción que la cultura jurídica ha dado a esta palabra. Vid. artículo 3 del Convenio Europeo para la Protección de los Derechos Humanos y Libertades Fundamentales: “Nadie podrá ser sometido a tortura ni a penas o tratos inhumanos o degradantes".

29 Vid. SsTC 221/2002, de 25 de noviembre, 220/2005, de 12 de septiembre, y 62/2007, de 27 de marzo. De las dificultades de concretar cuándo acontece el riesgo relevante para que la lesión pueda producirse, interesa mencionar el voto particular concordante del Juez Jambrek en la Sentencia del Tribunal Europeo de Derechos Humanos de 19 de febrero de 1998 (TEDH 1998/2) en el que sostiene certeramente que "ha llegado el momento de que la jurisprudencia del Tribunal respecto del artículo 2 Convenio [derecho a la vida y a la integridad física] evolucione (...) y defina las situaciones que implican un riesgo real y graven. 
contrario, y éste es uno de los extremos más destacados del pronunciamiento objeto de este comentario, no corren la misma suerte desafortunada los derechos a la intimidad personal y familiar en el ámbito domiciliario contenidos en el artículo 18.1 y 2 CE. Un derecho, por lo que se refiere en primer término a la intimidad personal, entendido como «un bien de la personalidad perteneciente al ámbito de la vida privada ${ }^{30}$. Derecho que, en tanto derivación de la dignidad de la persona (artículo 10.1 CE) implica "la existencia de un ámbito propio y reservado frente a la acción y el conocimiento de los demás, necesario según las pautas de nuestra cultura para mantener una calidad mínima de la vida humana y referido preferentemente a la esfera, estrictamente personal, de la vida privada o de lo íntimo ${ }^{31}$ ". Mientras, y en segundo lugar, la inviolabilidad del domicilio se establece "para garantizar el ámbito de privacidad de las personas, - ámbito en suma en el que los individuos, libres de toda sujeción a los usos y convenciones sociales, ejercen su libertad más íntima ${ }^{32}$ —, dentro del espacio limitado que la propia persona elige y que tiene que caracterizarse precisamente por quedar exento a las invasiones o agresiones exteriores ${ }^{33}$ ".

Como comprobaremos acto seguido, aquí sí, el sobrevuelo constante de aviones sobre la urbanización provoca, a juicio del máximo órgano jurisdiccional, una afección de estos derechos (fundamentos jurídicos noveno, décimo, undécimo y duodécimo) siendo «el ruido el elemento desencadenante de las vulneraciones alegadas por los recurrentes".

El análisis de la vulneración que el sobrevuelo de aeronaves provoca en la intimidad domiciliaria y personal de los vecinos de la urbanización nos sitúa de lleno ante el juego de las dos variables a los que nos referíamos en la introducción de este trabajo, a saber: tráfico aéreo y contaminación acústica. Y el modo en que el TS afronta y enfrenta el examen de la afección que provoca la contaminación acústica generada por el tráfico aéreo y que padecen los recurrentes pasa, en primer término, i) por la constatación de una serie de evidencias fácticas ya consideradas por la Sentencia de instancia y que, por ende, no se discuten. En segundo lugar, ii) por la determinación del carácter evitable o no de las trayectorias de vuelo de los aviones a la hora de realizar sus maniobras de aproximación sobrevolando la urbanización. Finalmente, la fundamentación del TS descansa, por mor de lo dispuesto en el artículo 10.2 $\mathrm{CE}^{34}$, iii) en la aplicación de la doctrina del Tribunal Europeo de Derechos Humanos (TEDH), en concreto la contenida en la Sentencia de 16 de noviembre de 2004 (TEDH 2004/68) en relación con el artículo 8 del Convenio

30 Vid. STC 170/87, de 30 de octubre.

31 Vid. SsTC 231/88, de 2 de diciembre, 197/91, de 17 de octubre, 20/92, de 14 de febrero, 219/92, de 3 de diciembre, 142/93, de 22 de abril, 117/94, de 10 de junio, 143/94, de 9 de mayo, 207/96, de 16 de diciembre, y 186/2000, de 10 de julio.

32 Vid. SsTC 22/84, de 17 de febrero, 137/85, de 17 de octubre, 94/99, de 31 de mayo, y $171 / 99$, de 27 de septiembre.

33 Vid. STS de 19 de diciembre de 1986 (RJ 1986/7165).

$34 \mathrm{El}$ artículo 10.2 CE como criterio interpretativo de los preceptos constitucionales tuteladores de los derechos fundamentales. Vid. SsTC 303/93, de 25 de octubre y 35/95, de 6 de febrero. 
Europeo para la protección de los Derechos Humanos y Libertades Fundamentales $(\mathrm{CEDH})$ que preceptúa que "Toda persona tiene derecho al respeto de su vida privada y familiar, de su domicilio y de su correspondencia".

La comprensión de la solución dada al conflicto planteado ante la instancia del TS obliga a tener en cuenta que los recurrentes, durante los años a los que se contrae el recurso inicialmente interpuesto ante el TSJ de Madrid (2002, 2003 y el primer semestre de 2004), soportaron el sobrevuelo de miles de aviones ${ }^{35}$ en frecuencias de tres minutos a una altura de entre 589 a 705 metros. Interesa recordar, como ya se ha tenido ocasión de precisar, que el problemático sobrevuelo de aviones sobre las viviendas de los recurrentes en la urbanización tiene lugar cuando el aeropuerto de Barajas opera en configuración sur por lo que a la pista 18R respecta ${ }^{36}$.

La importancia del pronunciamiento del TS radica en la distinta valoración dada y, por ende, en el diferente fallo propiciado de cara a la estimación parcial del recurso a partir de los datos que, a raíz de la práctica probatoria en la instancia, se extraen ya en la Sentencia del TSJ de Madrid. La situación fáctica, así considerada, es la que posibilita la ulterior determinación de los umbrales de ruido soportables y las condiciones de habitabilidad que se estiman mínimas y confortables para una persona en su propia vivienda.

i) En efecto, los datos indiscutidos de las mediciones que en su momento se aportaron con la demanda arrojan unos valores medios correspondientes al paso de aviones situados entre 63 decibelios (db) y $59.1 \mathrm{db}$, alcanzando los máximos un valor de $78 \mathrm{db}$ por la tarde y $77 \mathrm{db}$ por la mañana. Por otra parte, en la prueba pericial practicada en la instancia en diez domicilios distintos, los valores medios se situaban por debajo de $65 \mathrm{db}^{37}$. La realidad significativa de estos niveles de ruido no es por sí sola suficiente si no se toman en cuenta a su vez las distintas prescripciones normativas y ambientales existentes tanto para los niveles de ruido exterior, como para los niveles de ruido interior. De esta manera y para alcanzar a comprender los umbrales de ruido soportados por los recurrentes, en lo referido a los niveles de ruido exterior, el TS se hace eco de la DIA de 1996 sobre el proyecto de ampliación del aeropuerto de Barajas. En el epígrafe 2.1 "Medidas correctoras de ruido" de la DIA, que casualmente no incluye a la urbanización entre las zonas consideradas de afección sonora ${ }^{38}$ a los efectos de desarrollar sobre la misma el

35 Según los datos que el propio TS toma como ciertos, 18.865 aviones en 2002, 30.471 en 2003 y 7.096 en el primer semestre de 2004.

36 También, según los datos que el TS considera suficientemente probados, en el año 2002 se sobrevoló la urbanización 113 días entre las 7 y las 23 horas; en el año 2003, 105 días; y en el primer semestre de 2004, 19 días. De todos esos días, la configuración sur del aeropuerto de Barajas se prolongó durante toda la jornada en 14 días en el año 2002 y en 17 días en el año 2003.

37 Entre $61.1 \mathrm{db}$ y $51.3 \mathrm{db}$ con las ventanas de los domicilios abiertas y entre $49.7 \mathrm{db}$ y 38 $\mathrm{db}$ con las ventanas cerradas.

38 Como sorprendentemente tampoco la incluye la DIA de 2001 relativa al proyecto de ampliación del sistema aeroportuario de Madrid.. Pese a esa omisión, y como consta en el anexo IV de la DIA de 2001 "Resumen de las alegaciones de carácter ambiental más significativas presentadas du- 
Plan de Aislamiento Acústico que la propia DIA obligaba a aprobar ${ }^{39}$, se fija el límite de ruido en unos valores medios de $65 \mathrm{db}$ entre las 7 y las 23 horas y de $55 \mathrm{db}$ entre las 23 y las 7 horas. Unos valores que, en todo caso, se sitúan en unos niveles de exigencia menores que los dispuestos por la normativa autonómica y local ${ }^{40}$ pese a que, como recuerda la Sentencia del TSJ de Madrid en la instancia, dicha normativa no resulta de aplicación al caso por ir referida a emisores acústicos situados en el respectivo ámbito territorial de aplicación, autonómico y municipal, con exclusión expresa de las infraestructuras aeroportuarias de competencia estatal.

De otro lado y por lo que se refiere más propiamente dicho a las condiciones mínimas de habitabilidad de las viviendas, lo que nos conduce a valorar el llamado ruido interior, la normativa básica sobre edificación ${ }^{41}$ establece en el anexo 5 de Recomendaciones - epígrafe 5.1 «Nivel de inmisión de ruido aéreo" - un nivel máximo de inmisión en decibelios, que se recomienda no sobrepasar ${ }^{42}$ para los edificios tipo residencial privado, de $45 \mathrm{db}$

rante la información pública", el Ayuntamiento de Algete, la Asociación contra el ruido de Ciudad Santo Domingo, la Comunidad de propietarios de Ciudad Santo Domingo, y doscientos vecinos de la Urbanización Ciudad Santo Domingo formularon alegaciones contra el proyecto de ampliación.

39 La DIA de 1996 determinaba que en el Plan de Aislamiento Acústico, posteriormente aprobado por Resolución de 4 de noviembre de 1998 de la Dirección General de Calidad y Evaluación Ambiental, se incluyeran las viviendas construidas o con licencia de obra anterior a la fecha de la DIA - la urbanización tiene una antigüedad de treinta y cinco años- que vinieran afectadas por el ruido de las aeronaves con niveles equivalentes de presión sonora superiores a $65 \mathrm{db}$ durante el día (de 7:00 a 23:00 horas) y a 55 db de noche (de 23:00 a 7:00 h). La Comisión de Vigilancia del Ruido de 28 de junio de 1999 aprobó las zonas de afección sonora (huellas sonoras) entre las que no se incluía a la urbanización como una de las zonas delimitadas por las isófonas definidas en los niveles acústicos diarios continuos equivalentes anteriormente citados. Además, y de acuerdo con el propio Plan de Aislamiento Acústico, en los seis meses siguientes a su aprobación, AENA venía obligada a realizar los estudios necesarios — basados en mediciones precisas y reales del ruido originado por las operaciones aeroportuarias - para evitar la incidencia de las nuevas rutas y de la entrada en funcionamiento de la nueva pista.

40 Así, en el caso del Decreto 78/99, de 27 de mayo, por el que se regula el régimen de protección contra la contaminación acústica de la Comunidad de Madrid, los niveles de ruido exterior se sitúan en torno a los 65,60 o $55 \mathrm{db}$ en día y 50 o $45 \mathrm{db}$ por la noche. Mientras que en la Ordenanza municipal de Algete, publicada en el BOCM núm 15, de 18 de enero de 2003, reguladora de la protección de la atmósfera frente a la contaminación por ruidos y vibraciones, los niveles de ruido son de $55 \mathrm{db}$ por día y $45 \mathrm{db}$ por noche.

41 La Norma Básica de la Edificación NBE-CA-81, sobre condiciones acústicas en los edificios, aprobada por RD 1909/81, de 24 de julio, y posteriormente modificada por el RD 2115/82, de 12 de agosto y por la OM 29 de septiembre de 1988 del Ministerio de Obras Públicas y Urbanismo, está en la actualidad derogada pese a ser mencionada en la Sentencia del TS objeto de este comentario. Junto a la norma básica de la edificación NBE-CA-88, sobre condiciones acústicas en los edificios, la normativa actualmente vigente es el RD 1317/2007, de 19 de octubre, por el que se aprueba el documento básico "DB-HR Protección frente al ruido" del Código Técnico de la Edificación y que modifica el RD 314/2006, de 17 de marzo de 2006, por el que se aprueba el Código Técnico de la Edificación. Cabe apuntar además que el RD 1317/2007, de 19 de octubre ha sido posteriormente modificado por el RD 1675/2008, de 17 de octubre.

42 Sobre todo para evitar los efectos de los ruidos tanto en las personas como ante los eventuales daños que se pueden producir en los cristales de las viviendas por las ondas sónicas de los aviones. 
para las estancias de una vivienda durante el día (de las 8.00 a las 22.00 horas) y $40 \mathrm{db}$ durante la noche (de las 22.00 a las 8.00 horas), descendiendo para el caso de los dormitorios a $40 \mathrm{db}$ durante el día y $30 \mathrm{db}$ durante la noche. Pese a estas referencias, las mediciones realizadas por el perito en la instancia no discriminaron el ruido producido por los aviones del ruido de fondo producto de otras posibles fuentes emisoras, lo que fue determinante para la suerte de la demanda de los actores según el TSJ de Madrid, y ello a diferencia, como comprobaremos, del parecer del TS, para quien esos otros ruidos de fondo representan en todo caso "una parte mínima del volumen total". Estas mediciones alcanzaban unos valores que puntualmente sobrepasaban los $45 \mathrm{db}$ (con las ventanas de las viviendas cerradas) y claramente por encima de los $45 \mathrm{db}$ (con las ventanas abiertas). En línea con lo apuntado, el TS considera que sí ha habido infracción de los derechos a la intimidad domiciliaria y personal, dado que "las mediciones son efectivamente representativas de la situación padecida por los actores" al arrojar unos valores máximos por encima de $70 \mathrm{db}$ (incluso con las ventanas de las viviendas abiertas con valores de entre 65.9 y $78.3 \mathrm{db}$ ). Dichas mediciones, en suma, "son globalmente expresivas de una situación de contaminación acústica" dada la relevancia y singularidad que tienen, en supuestos como éste, los valores máximos de las mediciones ${ }^{43}$. Una relevancia y singularidad que resulta del hecho de que el ruido producto del sobrevuelo de aviones no es continuo, sino a intervalos, ni es tampoco constante, sino más bien aumenta progresivamente conforme se va aproximando el avión, alcanza el umbral máximo y disminuye paulatinamente en la medida en que la aeronave se aleja ${ }^{44}$. El ruido, así descrito como fuente permanente de perturbación de la calidad de vida de los recurrentes, produce una afección a la intimidad personal y familiar de los mismos y también a la inviolabilidad del domicilio.

El máximo órgano jurisdiccional se aparta así, con buen criterio a nuestro juicio, de la decisión del TSJ de Madrid, quien no consideró suficiente lo anterior para entender vulnerados los derechos del artículo 18.1 y 2 CE y ello porque, en el parecer de la Sala en la instancia, los ruidos soportados no re-

43 Aún partiendo de la necesaria independencia entre la consideración administrativa y civil sobre el ruido, interesa tener en cuenta cómo en el ámbito de las llamadas relaciones de vecindad existe el criterio conforme al cual la superación de los niveles máximos de ruido regulados por las ordenanzas municipales supone una presunción iuris tantum de la intolerabilidad civil de la inmisión acústica.

44 Las directrices y recomendaciones de la Organización Mundial de la Salud (OMS) en relación con las molestias que causa un ruido determinado dependen, como enfatiza el propio TS, de la superación del ruido ambiente en el caso de que el ruido sea constante, pero difícilmente cuando la molestia producida por el ruido varía con el tiempo, como sucede con la contaminación acústica de las aeronaves. Por esto mismo y por las características distinguidoras que presenta el ruido de los aviones, las mediciones a realizar, además de constatar los valores medios, deben atender necesariamente a los valores máximos y a los valores de exposición de ruido ( "Sound exposure level" o SEL), extremo este último que no tuvo en cuenta el TSJ de Madrid en la instancia. 
presentaban una molestia grave ${ }^{45}$, no eran constantes, persistentes o prolongados al no realizarse de noche, y finalmente porque los sobrevuelos no eran a baja altura (con una media de 655 metros). La Sala del TSJ alcanzó este resultado a partir de la doctrina del TC, representada, en ese pronunciamiento en la instancia, por la STC 119/2001, de 24 de mayo. Una doctrina según la cual la infracción del derecho fundamental reconocido en el artículo $18.1 \mathrm{CE}$ descansa, en lo sustancial, en su carácter determinante, y ello a raíz de su naturaleza prolongada, insoportable, y evitable. La cuestión aquí no es otra que valorar si la ruta seguida por un avión, sobre todo por lo que se refiere a las maniobras de despegue y de aterrizaje en el sobrevuelo de zonas habitadas, es o no una circunstancia insoportable y evitable.

ii) El problema del que parte la Sentencia del TSJ de Madrid no es otro que considerar que la aproximación al aeropuerto de Barajas en configuración sur resulta inevitable en relación con la causación de molestias por ruidos dado que las alternativas existentes ${ }^{46}$ —el sistema VOR/DME — sólo puede ser usado si las condiciones meteorológicas y de seguridad lo permiten. El sistema VOR/DME ${ }^{47}$, como sistema de referencia de navegación aérea del aeropuerto de Barajas, responde a una maniobra de aproximación a la pista 18R cuando el aeropuerto de Barajas opera en configuración sur que, aparte de estar autorizada por las autoridades competentes en términos de seguridad y recomendado por la condición segunda de la DIA de 1996 y la condición cuarta de la DIA de 2001, evita precisamente el sobrevuelo de la urbanización ${ }^{48}$ tal y como demandaban los recurrentes en la instancia a AENA y a la

45 Si bien la OMS considera una molestia grave o severa la exposición a ruidos de más de $55 \mathrm{db}$ durante dieciséis horas en el exterior y moderada la exposición en el mismo tiempo a ruidos de $35 \mathrm{db}$ en el interior de las viviendas, en el expediente, según recrea el propio TS, ya había constancia de mediciones realizadas por AENA que arrojaban valores superiores a los $65 \mathrm{db}$ de media.

46 Esta argumentación del TSJ de Madrid obliga a tener en cuenta la DIA de 2001 en la que, en su condición cuarta "Protección acústica", expresamente se insta a la DGAC y a AENA a estudiar rutas de aproximación (y de despegue) basadas en las técnicas de navegación aérea disponibles que permitan compaginar, por un lado, la necesaria ampliación de capacidad del aeropuerto para satisfacer el crecimiento de demanda de tráfico aéreo y, por otro, la minimización del impacto acústico sobre las urbanizaciones situadas en el entorno del aeropuerto.

$47 \mathrm{El} \mathrm{VOR/DME} \mathrm{es} \mathrm{una} \mathrm{red} \mathrm{terrestre} \mathrm{de} \mathrm{radioayuda} \mathrm{empleada} \mathrm{frecuentemente} \mathrm{en} \mathrm{la} \mathrm{nave-}$ gación aérea convencional y que, como sistema de guiado azimutal, permite realizar en áreas próximas a una pista de vuelo una maniobra de aproximación pero de no precisión (a diferencia del ILS o Sistema de Aproximación Instrumental) por venir conformada sólo por un guiado en el plano horizontal (guiado azimutal) pero sin proporcionar a la aeronave (como sí hace el ILS, tratándose por ello de un sistema de precisión) un plano o senda de descenso (guiado vertical). Esta maniobra de aterrizaje fue aprobada por la Comisión Interministerial de Defensa y Fomento el 6 de agosto de 2001 y tras su publicación en la AIP entró en vigor el 6 de septiembre de 2001.

48 De hecho, la Sentencia del TSJ de Madrid en la instancia da por cierto que todos los informes técnicos obrantes en autos coinciden en que la utilización de la maniobra de aterrizaje VOR/DME cuando el aeropuerto opera en configuración sur evita los sobrevuelos a baja altura sobre la urbanización. 
DGAC. Este sistema, de cara a realizar la maniobra de aproximación, es utilizado cuando los flujos de llegada de aeronaves al aeropuerto son inferiores a veintiséis a la hora ${ }^{49}$.

Sin perjuicio de la necesaria toma en consideración del emplazamiento más o menos seguro y sobre todo acertado de un aeropuerto, en atención a su idoneidad territorial y ambiental, extremo éste que aquí no se discute, las trayectorias del vuelo de los aviones, sobre todo en su fase final en maniobra de aproximación para tomar tierra, obligan a valorar, aparte los lógicos motivos operativos de seguridad, otros extremos como las condiciones meteorológicas y la congestión que presente el tráfico aéreo en un momento dado de cara a posibilitar la llegada escalonada de las aeronaves. Y sobre la base de estos presupuestos, frente al parecer del TSJ de Madrid, el TS no duda en sostener que la situación padecida por los recurrente "no era totalmente inevitable, , en la medida en que existen otras rutas de aproximación al aeropuerto de Barajas, incluso operando en configuración sur, que no incluyen el sobrevuelo de la urbanización afectada. De hecho, esta realidad es la que perfectamente puede constatarse en la DIA de 30 de noviembre de 2001 con ocasión del proyecto de ampliación del sistema aeroportuario de Madrid. En la condición cuarta, relativa a las medidas correctoras de ruido, se afirma que "siempre que las condiciones de seguridad aeronáutica lo permitan, las maniobras de aproximación en configuración sur se basarán en el VOR situado en San Sebastián de los Reyes, así como en las diferentes ayudas a la navegación aérea actuales o futuras situadas en el área Terminal de Madrid, a fin de reducir los niveles de contaminación acústica en las urbanizaciones situadas al norte del aeropuerto".

El TS considera, por lo expuesto, que la realidad de los sobrevuelos de aeronaves en sus trayectorias de aproximación al aeropuerto de Barajas cuando éste opera en configuración sur es indiscutible en lo que se refiere al paso de aviones a baja altura en intervalos de menos de tres minutos durante 235 días, varias horas al día en dos años y medio, con «unos picos de ruido que llegaron hasta $78.3 \mathrm{db}$ coincidiendo con el paso de los aviones con alteraciones de 21.6 a $43.5 \mathrm{db}$, superando los valores recomendados en el interior". Todo lo anterior conduce, en suma, a que "la perturbación causada por el ruido del que se viene hablando [sea] suficiente, por su entidad, naturaleza y duración, para generar molestias que lo trastornan [el derecho de los recurrentes a su intimidad domiciliaria y a desarrollar libremente su personalidad en el recinto donde tienen su morada] más allá de los límites aceptables ${ }^{50}$. El máximo

49 Como constata el propio TS en el fundamento jurídico décimo de la Sentencia objeto de comentario, la frecuencia del uso del sistema VOR/DME fue del 21,7\% en 2002, del 3,2\% en 2003 , y del 3,4\% en el primer semestre de 2004 .

50 Nótese cómo el propio TS, en la Sentencia de 26 de noviembre de 2007 (RJ 2007/8552), advierte que la persistencia durante dos años de ruidos "puede producir al ser humano un estado de crispación, que a todas luces le altera psíquicamente con obvias repercusiones físicas y le ocasiona la imposibilidad del disfrute de su domicilio y la dificultad de mantener unas mínimas condiciones para el desarrollo de la intimidad personal y material. 
órgano jurisdiccional, aún sin manifestarlo abiertamente, asume perfectamente la concurrencia de un interés económico en la actividad causante del ruido cual es el servicio de transporte aéreo. Pero no deja de ser menos cierto, y esto es lo verdaderamente relevante, que implícitamente también para el TS no consta que no se pueda armonizar la intimidad personal y la inviolabilidad del domicilio con el servicio de transporte aéreo de personas o mercancías instaurando en éste mecanismos, si no por entero silenciosos, sí al menos productores de menos emisiones de ruido. En este sentido, y en el marco de la necesaria limitación del vuelo nocturno a las aeronaves más ruidosas para la protección del bienestar de los vecinos de los municipios más próximos al aeropuerto, cabe destacar la Resolución del Ministerio de Fomento de 4 de abril de 2000 de convalidación del NOTAM ${ }^{51}$ CO351/00, de 25 de enero de 2000, por la que se acuerdan restricciones operativas nocturnas por razón del ruido en el aeropuerto de Barajas ${ }^{52}$. Esta Resolución ministerial valora, por un lado, los derechos individuales de los afectados y, por otra parte, las necesidades e intereses colectivos. De este modo, al sopesar ${ }^{53}$ los intereses económicos de las compañías aéreas y los perjuicios de orden humano y social que se derivan del ruido de los aviones para la calidad de vida de las personas que habitan en el entorno del aeropuerto, la Resolución hace prevalecer poderosamente «el interés público [concretado en el derecho al descanso de los habitantes de los municipios del entorno del aeropuerto frente al ruido nocturno] sobre el interés económico de las compañías aéreas que no

51 El NOTAM, como acto de comunicación de información aeronáutica en los términos que ya nos constan, se define por el Reglamento de circulación aérea como el "Aviso distribuido por medios de telecomunicaciones que contiene información relativa al establecimiento, condición o modificación de cualquier instalación aeronáutica, servicio, procedimiento o peligro, cuyo conocimiento oportuno es esencial para el personal encargado de las operaciones de vuelo". En definitiva, se trata de un acto administrativo adoptado con unas medidas de disciplina concretas para restringir las operaciones de aterrizaje y despegue de las aeronaves más ruidosas en horario nocturno en el aeropuerto de Barajas.

52 En concreto, las medidas restrictivas establecen prohibiciones de operaciones de despegue y aterrizaje para determinadas aeronaves, la autorización de nuevos permisos de vuelo para algunas aeronaves, y finalmente la adopción de un sistema de cuota de ruido total en la franja horaria entre las 0.00 y las 6.00 horas. Estas medidas originaron la interposición de un recurso contencioso-administrativo por la Asociación de Líneas Aéreas de España resuelto inicialmente por Sentencia de la Audiencia Nacional de 15 de noviembre de 2002 (JUR 2006/218945) y posteriormente en casación por la Sentencia del TS de 6 de mayo de 2005 (RJ 2005/4400). Cabe decir, además, que la aprobación de dichas medidas se situaban en línea con las adoptadas por la mayor parte de los aeropuertos comunitarios. Vid. más ampliamente sobre las restricciones de operaciones aéreas en horarios nocturnos la Decisión 1998/523, de 22 de julio, de la Comisión (Asunto VII/AMA/10/97) en relación con el acceso de las compañías aéreas al aeropuerto de Karlstad (Suecia).

53 Debe tenerse en cuenta que, aunque posterior a la aprobación de la NOTAM indicada en el texto principal, hoy día el artículo 4.2 del RD 1257/2003, de 3 de octubre, por el que se regulan los procedimientos para la introducción de restricciones operativas relacionadas con el ruido de los aeropuertos exige, cuando se estudie la adopción de alguna posible restricción operativa, tener plenamente en cuenta los costes y beneficios probables de las distintas medidas, así como las características específicas de cada aeropuerto. 
se verán altamente afectadas ya que el número de aviones a los que se restringe las operaciones nocturnas es mínimo ${ }^{54}$.

iii) Finalmente, a la estimación parcial del recurso, en lo que se refiere al reconocimiento de infracción de los derechos a la intimidad domiciliaria personal y familiar, contribuye la doctrina jurisprudencial del TEDH, principalmente concretada, en el pronunciamiento que venimos comentando, a partir de la Sentencia de 16 de noviembre de 2004 (TEDH 2004/68), que configura una noción amplia del ámbito de protección del derecho a la intimidad domiciliaria que se anuda a su reconocimiento en el artículo $8 \mathrm{CEDH}$. Sin perjuicio de la importancia que presenta la Sentencia de 16 de noviembre de 2004 (TEDH 2004/68), interesa también, de cara a la comprensión del fallo, y pese a que no es citada por el TS, la doctrina del TEDH sentada en hasta tres pronunciamientos distintos en relación directa con los ruidos producidos por los aviones en las instalaciones aeroportuarias situadas próximas a las viviendas de los afectados ${ }^{55}$.

Ese ámbito de protección de la intimidad domiciliaria, a partir de la doctrina del $\mathrm{TEDH}^{56}$, y concretado en el artículo $8 \mathrm{CEDH}$, protege contra aten-

54 También en la Sentencia del TEDH de 2 de octubre de 2001 (TEDH 2001/567), en un supuesto de ruido producido por el tráfico aéreo, se reconoce la violación del artículo 8 CEDH al decidir si una persona tiene la obligación de soportar una injerencia en forma de ruido bajo el pretexto de la protección del desarrollo social y económico del país. En este sentido, el TEDH manifiesta que no se ha alcanzado "un equilibrio justo entre el bienestar económico del país y el disfrute efectivo del derecho de los demandantes al respeto de su domicilio y de su vida privada y familiar. Es más, con anterioridad incluso, en el conflicto resuelto por la Sentencia del TEDH de 21 de febrero de 1990 (TEDH 1990/4), también en relación con el ruido generado por el tráfico aéreo en las inmediaciones del aeropuerto de Heathrow, el TEDH reconoció que, en la medida que el ruido de los aviones del aeropuerto disminuye la calidad de vida privada y el encanto y el disfrute del hogar de las personas que viven en las inmediaciones, es obligatorio tener en cuenta el artículo $8 \mathrm{CEDH}$, y ello pese a que sorprendentemente en el fallo de este último pronunciamiento citado el TEDH, por unanimidad, declara no tener competencia para conocer de la reclamación efectuada por los recurrentes con fundamento en el artículo $8 \mathrm{CEDH}$.

55 Esas tres Sentencias del TEDH se refieren a los ruidos padecidos por los recurrentes como consecuencia del tráfico aéreo generado por el aeropuerto londinense de Heathrow. Se trata de los pronunciamientos de 21 de febrero de 1990 (TEDH 1990/4), de 2 de octubre de 2001 (TEDH 2001/567), y de 8 de julio de 2003 (TEDH 2003/40), si bien en este último la Gran Sala del TEDH, "revisando" la Sentencia del propio TEDH de 2 de octubre de 2001, declara, sorprendente y peligrosamente en relación con la consolidada doctrina jurisprudencial previa, que no hay vulneración del artículo $8 \mathrm{CEDH}$. Junto a estos tres pronunciamientos cabe mencionar igualmente el asunto Arondelle (demanda 7889/77 y Resolución de la Comisión Europea de Derechos Humanos de 15 de julio de 1980) y el asunto Bags (demanda 9310/81 y Resolución de la Comisión Europea de Derechos Humanos de 16 de octubre de 1985), cuyas demandas fueron admitidas por el TEDH pero que no originaron un pronunciamiento del Tribunal por el acuerdo amistoso alcanzado por los recurrentes con el Gobierno británico.

56 Principalmente, como el propio TS se hace eco, derivada de la Sentencia de 16 de noviembre de 2004 (TEDH 2004/68) pero también concretada, entre otras, en las Sentencias de 21 de febrero de 1990 (TEDH 1990/4), de 9 de diciembre de 1994 (TEDH 1994/3), de 19 de febrero de 1998 (TEDH 1998/2), de 10 de noviembre de 2004 (TEDH 2004/85), de 26 de octubre de 2006 (TEDH 2006/61), de 2 de noviembre de 2006 (TEDH 2006/64), y de 5 de junio de 2007 (TEDH 2007/38). 
tados graves al medio ambiente que puedan afectar al bienestar de una persona y privarle de gozar de su domicilio, menoscabando su vida privada y familiar, y lo más importante de todo, sin que sea necesario poner en grave peligro la salud de los afectados ${ }^{57}$. De hecho, éste es el valor añadido que aporta el derecho a la intimidad domiciliaria personal y familiar como posteriormente el propio TC —en la STC 119/2001, de 24 de mayo y en la STC 16/2004, de 23 de febrero-y el TS —en Sentencias de 10 de abril de 2003 (RJ 2003/4920), de 29 de mayo de 2003 (RJ 2003/5366), y de 12 de marzo de 2007 (RJ 2007/2580) — han enfatizado al sostener que "ciertos daños ambientales, en determinados casos de especial gravedad, aun cuando no pongan en peligro la salud de las personas, pueden atentar contra su derecho al respeto de su vida privada y familiar privándola del disfrute de su domicilio en los términos del artículo 8.1 del Convenio de Roma". Es así como el CEDH, por la acción de su artículo 8, como instrumento normativo vivo que debe ser leído a la luz de las condiciones de vida actuales ${ }^{58}$, es objeto de una reinterpretación gradual que permite incluir en él los más modernos derechos ambientales como una suerte de nueva generación de derechos humanos ${ }^{59}$.

Sobre la base de este reconocimiento, la prevalencia del derecho a la vida privada y familiar en el ámbito domiciliario ha encontrado en la doctrina del TEDH, y a través de ella en la del TC y el TS, un alcance inédito hasta el momento, máxime cuando todas las vulneraciones a la inviolabilidad del domicilio tradicionalmente pasaban por afecciones materiales o corporales, principalmente mediante la entrada no autorizada en el domicilio de una persona. Empero, en la Sentencia del TEDH de 16 de noviembre de 2004 (TEDH 2004/68) se apuesta por una reinterpretación del alcance de la intimidad domiciliaria que, previamente acomodada por el TC, el propio TS hace suya en el caso que nos ocupa. De este modo, la virtualidad actual del derecho a la intimidad domiciliaria sobre la base del artículo $8 \mathrm{CEDH}$ pasa también por la tutela del espacio físico domiciliario frente a los atentados medioambientales que dificulten gravemente su normal disfrute. Ahora bien, como determina el TEDH en la Sentencia de 22 de mayo de 2003 (TEDH 2003/25), "el elemento crucial que debe estar presente para determinar si, en las circunstancias de un caso, la contaminación medioambiental ha afectado de manera adversa a uno de los derechos que protege el apartado 1 del artículo 8 [CEDH] es la existencia de un efecto dañino en la esfera privada o familiar de la persona y no simplemente el deterioro general del medio ambiente".

57 Como por el contrario, recuérdese, sí sucede para el reconocimiento de lesión del derecho a la vida y a la integridad física.

58 Vid. Sentencias del TEDH de 9 de octubre de 1979 (TEDH 1979/3) y de 23 de marzo de 1995 (TEDH 1995/3).

59 La Sentencia del TEDH de 8 de julio de 2003 (TEDH 2003/40) declara en este mismo sentido que "el Convenio no reconoce expresamente el derecho a un medio ambiente sano y tranquilo, pero cuando una persona padece directa y gravemente el ruido u otras formas de contaminación, se puede plantear una cuestión desde el punto de vista del artículo 8". 
Con este presupuesto, el individuo tiene derecho a una situación de bienestar personal, o lo que es lo mismo "al respeto de su domicilio, concebido no sólo como el derecho a un simple espacio físico sino también a disfrutar, con toda tranquilidad, de dicho espacio ${ }^{60} "$ y por ende de lo que en él hay de emanación de la persona que lo habita ${ }^{61}$, dado que el domicilio es precisamente el lugar, el espacio físico concreto en el que se desarrolla la vida privada y familiar. La protección de la intimidad domiciliaria personal y familiar obliga no sólo a hacer frente a las injerencias de terceras personas como presupuesto típico del ámbito de desarrollo del mencionado derecho. La reinterpretación de su contenido a la luz de la doctrina europea y constitucional obliga también a esgrimir su protección frente a los riesgos que puedan surgir en una sociedad tecnológicamente avanzada a resultas de "vulneraciones inmateriales o incorporales" como las que pueden tener lugar a partir de emisiones, olores, radiaciones electromagnéticas ${ }^{62}$, destellos luminosos ${ }^{63}$ y por supuesto los ruidos ${ }^{64}$. Con ello, el TS, aún sin reconocerlo expresamente ${ }^{65}$, deja abierta la puerta a que los ruidos, cuando resultan excesivos y molestos al sobrepasar el umbral aceptable para la audición humana, se incardinen dentro de las intromisiones ilegítimas previstas en el artículo 7 de la LO 1/82, de 5 de mayo, de protección civil del derecho al honor, a la intimidad personal y familiar y a la propia imagen por no constituir este precepto, al albur de la doctrina legal, un "numerus clausus". De esta forma y sobre la base de que la protección de la intimidad no se reduce a evitar ni los supuestos de divulgación de la vida privada ni los casos de penetración no autorizada en el ámbito de desarrollo de la vida privada, otras nuevas manifestaciones

60 Vid. Sentencia del TEDH de 16 de noviembre de 2004 (TEDH 2004/68).

61 Vid. STC 22/84, de 17 de febrero.

62 Vid. Decisión del TEDH de 6 de septiembre de 2005 (TEDH 2005/87).

63 Resulta interesante mencionar en este sentido el recurso de apelación resuelto por la Sentencia de la Audiencia Nacional de 16 de octubre de 2007 (JUR 2007/346180) en el que los recurrentes solicitaban a AENA el cese en la utilización del sistema instrumental de aterrizaje "ILS" implantado en el aeropuerto de Peinador en Vigo, como consecuencia de las proyecciones lumínicas que desprendía el sistema de balizamiento del aeropuerto sobre la vivienda de los demandantes y la eventual existencia de una intromisión lumínica en el domicilio de los demandantes con posible vulneración del derecho fundamental al artículo $18 \mathrm{CE}$.

64 El ruido, como se precisa en la STC 119/2001, de 24 de mayo y en la STC 16/2004, de 23 de febrero, "puede llegar a representar un factor psicopatógeno destacado en el seno de nuestra sociedad y una fuente permanente de perturbación de la calidad de vida de los ciudadanos. Así lo acreditan, en particular, las directrices marcadas por la Organización Mundial de la Salud sobre el ruido ambiental cuyo valor como referencia científica no es preciso resaltar".

65 Aunque sí lo llegó a manifestar en la STS (Sala de lo Civil) de 29 de abril de 2003 (RJ 2003/3041), a raíz del reconocimiento constitucional de los derechos fundamentales con tutela jurídica reforzada y la consecuente superación de las limitadas soluciones propiciadas por las relaciones inter privatos de los artículos 590, 1902 y 1908 del Código Civil, precisamente en relación con inmisiones sonoras excesivas y la intromisión ilegítima al derecho fundamental a la intimidad y a la inviolabilidad del domicilio. En este sentido, "el derecho a la intimidad ha cobrado una mayor dimensión que, en cierto modo, espiritualiza su finalidad, relacionándolo con el ámbito propio de la personalidad, que debe ser protegido de cualquier injerencia o inmisión que pueda perturbarlo expresamente dentro del recinto domiciliario". 
— como el ruido_ que alteran gravemente el entorno vital, personal y familiar más íntimo pueden reputarse como intromisiones ilegítimas - actos atentatorios a la intimidad - frente a las cuales cabe y es obligada la tutela judicial a partir de la jurisprudencia del $\mathrm{TEDH}^{66}$.

Es así como, en la recreación que hace el propio TS de la vulneración del artículo $8 \mathrm{CEDH}$, el máximo órgano jurisdiccional "corrige" la decisión del TSJ de Madrid con el propósito último de evitar lo que podríamos dar en llamar como "enfoques indebidamente formalistas", sirviéndonos de la expresión empleada por el propio TEDH. Precisamente, la superación formal de la carga de la prueba sobre la intensidad del ruido en el interior del domicilio condujo al TEDH, en el caso de la Sentencia de 16 de noviembre de 2004 (TEDH 2004/68), a estimar innecesaria la prueba, y con ella la acreditación del nivel de ruido en el interior de la vivienda de la demandante, ya que de lo contrario esa exigencia hubiera sido muy formalista ${ }^{67}$. Esto debido a que teniendo en cuenta las circunstancias del caso concreto, las propias autoridades municipales habían declarado como zona acústicamente saturada el lugar donde se ubicaba la residencia de la recurrente, amén de que los propios servicios técnicos municipales habían comprobado en varias ocasiones el exceso de ruido existente. Por ello resulta inadecuado requerir a una persona que vive en un área acústicamente saturada aportar la evidencia de un hecho que la autoridad local conoce oficialmente.

En el caso que nos ocupa, la constatación, como ya se ha tenido ocasión de comprobar, de unos niveles de ruido suficientemente expresivos de la situación que venían padeciendo los recurrentes durante más de dos años, obliga a entender vulnerado per se el derecho a la intimidad del domicilio y a la vida personal. Para ello resulta particularmente destacado plantear que incluso no existiendo, en el caso de la zona en la que habitan los recurrentes en la urbanización $^{68}$, una declaración formal de saturación acústica, sí que se podría llegar a plantear la existencia de una declaración material de la misma en consideración a la acreditación de las circunstancias del caso en concreto, conforme ya ha tenido ocasión de manifestar en alguna ocasión el propio TS $^{69}$.

La virtualidad del artículo $8 \mathrm{CEDH}$ aparece reforzada, a mayor abundamiento, por el hecho de que el sobrevuelo de aeronaves difícilmente parece tener cabida en alguna de las excepciones que el propio artículo $8 \mathrm{CEDH}$ es-

66 Téngase en cuenta que ya en la Sentencia del TEDH de 9 de diciembre de 1994 (TEDH 1994/3), con posterior proyección en la STC 119/2001, de 24 de mayo, se incluyeron, en el núcleo de la intimidad-protección del domicilio, las intromisiones sonoras por considerar que el ruido excesivo supone una violación del derecho al respeto a la vida privada y familiar.

67 También el TS —-Sentencia de 12 de noviembre de 2007 (RJ 2007/8394) — sostiene que la eventual vulneración de los derechos reconocidos en el artículo 18.1 y 18.2 CE "no puede quedar subordinada, como si de un requisito formal inexcusable se tratase, a que la medición de los índices sonométricos se haya realizado en el interior de la vivienda".

68 Recuérdese que la urbanización no se encuentra dentro de las zonas de afección sonora (huellas sonoras) delimitadas por la Comisión de Vigilancia del Ruido de 28 de junio de 1999.

69 Vid. Sentencia de 12 de marzo de 2007 (RJ 2007/2580). 
tablece $^{70}$, lo que obliga en última instancia al TS a reconocer la estimación parcial del recurso contencioso-administrativo en su día interpuesto ante el TSJ de Madrid. En buena lógica, la inactividad de la Administración, en este caso de AENA y la DGAC, de cara a evitar el resultado lesivo, comporta a juicio del máximo órgano jurisdiccional, la declaración de la vulneración del derecho. De acuerdo por tanto a una consolidada doctrina jurisprudencial del propio $\mathrm{TS}^{71}$, que asume la doctrina anterior del TC y del TEDH, una exposición prolongada a determinados niveles de ruido que puedan objetivamente calificarse como evitables ${ }^{72}$ o insoportables debe merecer la protección dispensada al derecho fundamental a la vida personal y familiar, en el ámbito domiciliario. Ello en la medida que impida o dificulte gravemente el libre desarrollo de la personalidad - precisamente en el lugar que debe estar a salvo de toda intromisión o injerencia no consentida por su titular o no autorizada por la Ley- y haya podido ser acreditado que la lesión o el menoscabo sufridos provienen de actos u omisiones de la Administración a los que sea imputable en última instancia la lesión producida.

Finalmente, y sin perjuicio del derecho de los recurrentes a que cese esa situación, extremo éste complejo de materializar en la práctica tratándose del sobrevuelo de aviones, el fallo del TS reconoce una indemnización de 6.000 euros como compensación por los perjuicios sufridos. Como el propio TS $^{73}$ ha tenido ocasión de reconocer en relación con los problemas generados por la contaminación acústica, "el pleno y eficaz restablecimiento del derecho fundamental vulnerado exige ciertamente, para que su tutela no sea teórica, una indemnización por los daños y perjuicios sufridos a causa de dicha vulneración". Dicha indemnización debemos presuponer, así pues, que debe compensar los daños producidos, representados, por otra parte, en la seguridad que proporciona el valladar del propio domicilio y, por ende, en la incomodidad y por qué no, sufrimiento a la hora de no poder hacer uso del mismo en condiciones aptas para el libre desarrollo de la personalidad. Es por ello que la indemnización, —6.000 euros- presumimos que debe haber so-

70 “No podrá haber injerencia de la autoridad pública en el ejercicio de este derecho, sino en tanto en cuanto esta injerencia esté prevista por la ley y constituya una medida que, en una sociedad democrática, sea necesaria para la seguridad nacional, la seguridad pública, el bienestar económico del país, la defensa del orden y la prevención del delito, la protección de la salud o de la moral, o la protección de los derechos y las libertades de los demás".

71 Vid. Sentencias del TS de 2 de junio de 2008 (RJ 2008/5470), de 26 de noviembre de 2007 (RJ 2007/8552), de 12 de noviembre de 2007 (RJ 2007/8394), de 12 de marzo de 2007 (RJ 2007/2580), de 29 de mayo de 2003 ((RJ 2003/5366), y de 10 de abril de 2003 (RJ 2003/4920).

72 En el fondo de la cuestión aquí debatida se plantea el carácter de los ruidos provocados por las aeronaves y, por ende, su naturaleza evitable o no. En este sentido y como muestra del distinto parecer adoptado todavía por los Tribunales, el TSJ de Cataluña, en la Sentencia de 21 de octubre de 1999 (Sala de lo contencioso-administrativo, Sección 2. ${ }^{a}$, recurso 2937/98), en línea con la decisión del TSJ de Madrid en la Sentencia de 31 de enero de 2006 (RJCA 2007/184), sostiene que, habiendo ruidos evitables mediante su erradicación total o mediante la adopción de medidas que los hagan más soportables, existen otros que son inevitables en nuestra civilización "en cuyo último campo deben incluirse los aviones".

73 Vid. Sentencia de 29 de mayo de 2003 (RJ 2003/5366). 
pesado las perturbaciones que como consecuencia del sobrevuelo de aviones se produjeron en las viviendas y en el entorno más inmediato de los recurrentes, así como las consecuencias que para su vida comportaron durante el período que las mismas duraron.

\section{CONCLUSIONES}

¿Tiene prioridad la protección de la salud y el bienestar domiciliario de las personas frente al desarrollo legítimo de una actividad económica como el transporte aéreo o más bien son inevitables las molestias del tráfico aéreo dadas las ventajas que reporta para la ciudadanía en su conjunto y la economía de un país? Asistimos a un nuevo conflicto en el que el TS se tiene que pronunciar $^{74}$ y para ello la doctrina del TEDH representa un punto importante a considerar. En este sentido, el TEDH, en la Sentencia de 21 de febrero de 1990 (TEDH 1990/4), se hace eco de las manifestaciones de la Comisión Europea de Derechos Humanos conforme a las cuales "la existencia de grandes aeropuertos internacionales, incluso en zonas urbanas muy pobladas, y el incremento del empleo de los aviones a reacción se han hecho indudablemente necesarios para el bienestar económico del país". Qué duda cabe que este tipo de consideraciones igualmente pueden proyectarse al aeropuerto de Madrid-Barajas. A priori, así pues, la explotación comercial de un aeropuerto y el uso del mismo por parte de las compañías aéreas constituyen un fin legítimo que difícilmente justifican que puedan suprimirse totalmente las repercusiones desfavorables que el tráfico aéreo generado por aquél ocasiona en su entorno más inmediato. Ahora bien, como también se reconoce en las Sentencias del TEDH de 2 de octubre de 2001 (TEDH 2001/567) y de 8 de julio de 2003 (TEDH 2003/40), "en un campo tan sensible como el de la protección medioambiental, la mera referencia al bienestar económico del país no es suficiente para superar los derechos de los demás". La contraposición entre la importancia que para la economía nacional representa la industria del transporte aéreo y de la aviación en su conjunto y, por otro lado, el respeto del derecho a la vida privada y familiar propicia la apertura de un intrincado dilema a la hora de alcanzar el justo medio kantiano entre los intereses en disputa de una persona o grupo de personas y los de la sociedad en su conjun-

$74 \mathrm{El}$ TS se ha tenido que pronunciar directamente sobre los ruidos generados por la actividad aeroportuaria, además de en la Sentencia objeto del comentario, en las Sentencias de 27 de abril de 2004 (RJ 2004/2826) y de 6 de mayo de 2005 (RJ 2005/4400). No es ésta además una cuestión inédita tampoco en otras instancias jurisdiccionales. Así, puede comprobarse en la Sentencias del Juzgado de lo contencioso-administrativo n ${ }^{\circ} 2$ de Bilbao de 3 y 4 de mayo de 2006 (RJCA 2006/322 y JUR 2006/150917); la Sentencia del TSJ del País Vasco de 11 de junio de 2007 (RJCA 2007/794), e incluso por lo que respecta al aeropuerto de Barajas, el propio TSJ de Madrid se ha pronunciado, además de en la Sentencia de 31 de enero de 2006 (RJCA 2007/184) que origina el recurso de casación resuelto por la Sentencia del TS de 13 de octubre de 2008, también en las Sentencias de 4 de junio de 2008 (JUR 2008/233514) y de 9 de julio de 2008 (RJCA 2008/399). 
to. Por ello, como advierten los dos últimos pronunciamientos citados del TEDH, "debe exigirse a los Estados que minimicen, hasta donde sea posible, la injerencia en estos derechos, intentando encontrar soluciones alternativas y buscando, en general, alcanzar los fines de la forma menos onerosa para los derechos humanos".

Esas soluciones alternativas y las medidas necesarias a adoptar para reducir el ruido generado por el tráfico aéreo y garantizar con ello la conformidad con el CEDH entran dentro del margen de apreciación que se reconoce a los Estados tal y como el TEDH tiene declarado desde la Sentencia de 21 de febrero de 1990 (TEDH 1990/4). El problema radica, así expuesto, en determinar cuándo y cómo se han adoptado las medidas necesarias para proteger la situación de las personas que viven en núcleos cercanos a los aeropuertos. En honor a la verdad, se ha avanzado mucho en el proceso de minoración del impacto acústico generado por las operaciones aéreas de despegue y aterrizaje $\mathrm{e}^{75}$ en los aeropuertos y ello no sólo mediante la adopción de normas estrictas que contemplan restricciones operativas, sino incluso alcanzando a la retirada de las aeronaves más ruidosas y procediendo a la zonificación de las áreas más próximas al aeropuerto en función de su distinta exposición al ruido ${ }^{76}$.

Pero aún así y pese a todo el elenco de medidas expuestas, se siguen ocasionando serias perturbaciones en el caso de los habitantes de las zonas más afectadas por el sobrevuelo continuo de aeronaves como el que ha dado pie al pronunciamiento del TS objeto de este comentario. El problema por tanto subyace no en la existencia de una injerencia por parte de alguna

75 Así por ejemplo la homologación fónica de aeronaves, restricciones de tráfico aéreo nocturno, introducción de itinerarios o trayectorias preferentes de ruido, uso alternativo de pistas, la introducción de pendientes mínimas para las aeronaves que despegan y de procedimientos de poca potencia o poca resistencia aerodinámica para la aproximación de aeronaves en vistas al aterrizaje, derechos de aterrizaje en función del ruido de las aeronaves, subvenciones y medidas compensatorias para el aislamiento acústico de viviendas, etc.

76 De conformidad con la DIA de 1996, el 4 de noviembre de 1998 se aprobó el Plan de aislamiento acústico de la ampliación del aeropuerto de Barajas. Bajo la égida de ese Plan de aislamiento acústico se han llevado a cabo actuaciones en alrededor de 12.000 viviendas llegando al caso incluso de materializar medidas compensatorias consistentes en el traslado de vecinos, cuyas viviendas tenían una exposición al ruido superior a los niveles fijados por las DIA de 1996 y 2001 , a un nuevo domicilio en otra zona del mismo municipio y en condiciones equivalentes cuando resultaba técnicamente inviable el aislamiento acústico eficaz de las viviendas. Por si fuera poco lo anterior, la Comisión de Seguimiento de las Obras de Ampliación del Aeropuerto de Barajas (CSAM), en la que están representados la Comunidad de Madrid y los Ayuntamientos afectados por las obras de ampliación - entre los que casualmente no se encuentra el de Algete- ha optado por determinados esquemas operacionales de rutas y uso de pistas de vuelo cuyo objeto es minimizar el impacto de las operaciones aéreas en el entorno del aeropuerto, tal y como prescribe la Resolución de 30 de agosto de 2006 de la DGAC por la que se introducen restricciones operativas en el aeropuerto de Barajas. En concreto, todos los esfuerzos se han centrado en paliar la problemática generada por la "dispersión de trayectorias", fenómeno especialmente acuciante como consecuencia de la escasa separación entre la trayectoria nominal y las diferentes urbanizaciones y núcleos poblacionales situados en el área de influencia del aeropuerto y que no han permitido otras opciones de diseño más alejadas de los mismos. 
autoridad pública en la que podemos dar en denominar como vertiente ambiental de los derechos fundamentales sino más bien la cuestión radica en si la Administración ha tomado o no, en tanto que obligación positiva, las medidas razonables y adecuadas a su alcance para proteger los derechos de los demandantes.

En línea con lo anterior, la estimación del recurso por el TS no pasa porque cesen como tales los sobrevuelos de aeronaves, sino más bien que cesen los ruidos que, como consecuencia del sobrevuelo, sufren los vecinos en sus viviendas exigiendo a AENA la adopción de las medidas que resulten adecuadas a tal fin. De este modo, la falta de concreción por el TS, dada la imposibilidad marcada por el artículo 71.2 LJCA, de cómo hacer cesar la situación que vienen padeciendo los recurrentes deja en manos de la Administración la adopción de las medidas precisas para que cese la causa de la lesión ${ }^{77}$. Quizás la solución pase entonces por el empleo del sistema de aproximación VOR/DME que, precisamente, evita el sobrevuelo por la urbanización y que, recuérdese, es el método preferente en la DIA, aunque no obligatorio, cuando las condiciones meteorológicas y de seguridad lo aconsejan. El carácter evitable o no del ruido a consecuencia del carácter evitable o no de la trayectoria seguida por las aeronaves cuando el aeropuerto opera en configuración sur deja abierto el dilema de la preeminencia o no de la seguridad aérea frente a las consideraciones estrictamente ambientales. Sea como fuere, la protección que garantiza la actuación jurisdiccional del TS en salvaguarda del derecho a la vida privada y familiar que se desarrolla en el ámbito reservado del domicilio particular debe ser congruente con su contenido constitucional para que pueda satisfacerse de forma real y efectiva ${ }^{78}$.

Pero en todo caso, detrás de este importante pronunciamiento del TS nos asalta la duda de saber si ha cesado o puede cesar el sobrevuelo de los aviones a baja altura por la urbanización pese a la estimación parcial de las pretensiones de los recurrentes. De hecho, al día siguiente de conocerse el fallo del TS seguían produciéndose sobrevuelos, anunciándose por parte del Ayuntamiento de Algete la intención de sancionar a todas las aeronaves que sobrepasaran los niveles de ruido dispuestos por su Ordenanza municipal de 2003. A tal fin interesa tener en cuenta que, pese a las dificultades de aplicar en este caso la Ordenanza municipal en atención a su ámbito de aplicación -que expresamente excluye a las infraestructuras aeroportuarias de compe-

77 Interesa recordar ahora, como planteaba el Magistrado Garrido Falla en el voto particular concurrente a la STC 119/2001, de 24 de mayo, "hasta qué punto la Administración pública requerida está obligada a dispensar la protección que de ella se solicita".

78 Téngase en cuenta que el propio TS en la Sentencia (Sala 1ª) de 29 de abril de 2003 (RJ 2003/3041) manifiesta que "el derecho a la intimidad reclama para su ejercicio pacífico, muy especialmente, dentro del recinto domiciliario y su entorno, un ámbito inmune frente a las agresiones perturbadoras, procedentes del exterior, que no exijan el deber específico de soportarlas, entre las que se encuentran, a no dudarlo, los ruidos desaforados y persistentes, aunque estos procedan, en principio, del desarrollo de actividades lícitas que dejan de serlo, cuando se traspasan determinados límites". 
tencia estatal - el responsable de las infracciones relativas a la disciplina del tráfico aéreo en materia de ruido ${ }^{79}$, a partir de lo dispuesto en el artículo 52.1.d) de la Ley de seguridad aérea, es la compañía aérea, el explotador u operador de la misma ${ }^{80}$, o incluso el piloto al mando de la aeronave con la que se haya cometido la infracción.

Frente a esa hipotética responsabilidad de los operadores — compañías o pilotos - interesa también precisar cuándo y cómo se podría desencadenar la eventual responsabilidad patrimonial de la Administración, en este caso, concretada en AENA y la DGAC. Pues bien, en la medida en que no se hubiera reconocido por el TS la violación de los derechos fundamentales del artículo 18.1 y 18.2 CE, o por sí sola la declaración de inexistencia de violación del derecho a la vida y a la integridad física del artículo $15 \mathrm{CE}$, dicho escenario podría situarnos, a nuestro juicio, ante una mera petición indemnizatoria motivada por la pasividad o inactividad administrativa como consecuencia de los sobrevuelos de aeronaves. Esta petición indemnizatoria, formalizada jurídicamente a través de una reclamación de responsabilidad patrimonial de la Administración en los términos dispuestos por los artículos 139 y siguientes de la Ley 30/92, de 26 de noviembre, de Régimen Jurídico de las Administraciones Públicas y del Procedimiento Administrativo Común, nos situaría ante una cuestión propia de legalidad ordinaria a resolver por una vía procedimental también ordinaria ${ }^{81}$.

El interés de esta otra vía alternativa ordinaria, como son los casos de reclamaciones de responsabilidad patrimonial de la Administración, radica en el hecho de que en los mismos no opera la necesidad de acreditar que la exposición continuada a unos niveles intensos de ruido ha puesto en peligro grave e inmediato la salud de las personas como imperiosamente acontece a los efectos de tener por lesionado el artículo 15 CE. Así, por ejemplo, el con-

79 Las infracciones pueden ser muy graves (artículo 47.3.1 de la Ley de seguridad aérea), por incumplir las restricciones de sobrevuelo o de altitud en zonas de especial sensibilidad acústica definidas en los procedimientos de disciplina de tráfico aéreo en materia de ruido, o graves (artículo 47.2.2 y 3 de la Ley de seguridad aérea) por ejecutar rutas de llegada no autorizadas, realizar maniobras no autorizadas que impliquen superar la desviación máxima permitida respecto a la ruta de servicio de tránsito aéreo definida para dicha maniobra, o superar los niveles máximos de ruido definidos en las trayectorias y puntos establecidos en los procedimientos de disciplina del tráfico aéreo.

80 Nuestra legislación es así mucho más estricta y garantista que la legislación británica donde el artículo 76.1 de la Ley de aviación civil de 1982 limita considerablemente la responsabilidad de las compañías aéreas siempre y cuando los aviones vuelen a una altura razonable al prescribir dicho precepto que "no se podrá ejercitar ninguna acción por perturbaciones o molestias únicamente por razón del vuelo de un avión sobre cualquier propiedad a una altura sobre el suelo que, teniendo en cuenta el viento, las condiciones atmosféricas y cualquier otra circunstancia pertinente, incluidas las incidencias habituales en el tráfico aéreo, sea razonable siempre que las disposiciones de las normas de navegación aérea se hayan cumplido debidamente".

81 En la que, además de acreditar la concurrencia de los requisitos necesarios para posibilitar tal declaración de responsabilidad de la Administración, debiera tenerse en cuenta el plazo de prescripción previsto en el artículo 142.5 de la Ley 30/92, de 26 de noviembre. 
flicto resuelto, con estimación parcial del recurso, por la Sentencia de la Audiencia Nacional de 23 de noviembre de 2004 (JUR 2005/231103) en que se discute la reclamación de responsabilidad del recurrente derivada de un retraso de AENA que provocó los daños por los que reclama aquél, al tener que soportar unos niveles de ruido superiores a los legalmente establecidos una vez superado el plazo de seis años que AENA tenía, de acuerdo con la DIA y el Plan de Aislamiento Acústico de la obra de ampliación del aeropuerto de Barajas, para ejecutar las medidas correctoras en la vivienda del demandante. En este pronunciamiento, la Audiencia Nacional reconoce la efectividad del daño a los efectos de la demanda de reclamación de responsabilidad patrimonial desde el momento en que se constata fehacientemente que el inmueble del recurrente se ubica en una zona en la que se superan los niveles máximos de ruido permitidos legalmente. Este hecho, a juicio de la Audiencia Nacional "por sí mismo supone un perjuicio para la salud, derivado de un medio ambiente inadecuado; sin que sea preciso que el actor acredite trastornos físicos o psíquicos o secuelas, que de ser acreditadas permitirían cuantificar el quantum indemnizatorio en mayor medida pero no eliminar el perjuicio que supone soportar ruido por encima de niveles acústicos legalmente establecidos como máximos".

La Sentencia en la instancia del TSJ de Madrid declaró en el caso que nos ha ocupado que "no cualquier infracción del ordenamiento jurídico en materia de ruidos ni cualquier desviación de los márgenes normativamente establecidos o recomendados supone una lesión del derecho fundamental a la intimidad domiciliaria”. Empero, cabe recordar que la Exposición de Motivos de la LJCA, al tiempo de recrear las novedades más importantes que supone la regulación del amparo judicial ordinario ${ }^{82}$ respecto de la regulación anterior establecida en la Ley 62/78, de 26 de diciembre, destaca que "la más relevante novedad es el tratamiento del objeto del recurso - y por tanto de la Sentencia- de acuerdo con el fundamento común de los procesos contenciosoadministrativos, esto es, contemplando la lesión de los derechos susceptibles de amparo desde la perspectiva de la conformidad de la actuación administrativa con el ordenamiento jurídico. La Ley pretende superar, por tanto, la rígida distinción entre legalidad ordinaria y derechos fundamentales, por entender que la protección del derecho fundamental o libertad pública no será factible, en muchos casos, si no se tiene en cuenta el desarrollo legal de los mismos ${ }^{83}$ ".

82 En virtud de una consolidada doctrina jurisprudencial del TS, "la finalidad del amparo judicial es comprobar si el acto o disposición de la Administración que se impugna afecta o no a la esencia o ejercicio de un derecho fundamental, no siendo posible abrir el procedimiento de [amparo judicial] para resolver asuntos de legalidad ordinaria". Vid. SsTS de 7 de junio de 1991 (RJ 1991/4943), de 18 de enero de 1994 (RJ 1994/185) y de 28 de abril de 1994 (RJ 1994/3175).

83 Como el propio TS ha reconocido, precisamente en relación con la contaminación acústica y la eventual afección del derecho a la intimidad domiciliaria y personal en la Sentencia de 12 de marzo de 2007 (RJ 20072580), "las cuestiones de legalidad ordinaria se encuentran en ocasiones de tal modo entrelazadas con el ámbito propio de los derechos fundamentales que el 
Con todo, y pese a la relevancia del fallo del TS, se nos antoja todavía escaso el empuje jurisprudencial dispuesto de cara a la protección de ciertos derechos fundamentales ante las afecciones acústicas que pueden llegar a padecerse como consecuencia de las operaciones de tráfico aéreo. Sin duda, el caballo de batalla se sitúa en la integridad física y la salud de las personas, dada la tangible separación que todavía se aprecia entre una y otra en el pronunciamiento objeto de este comentario así como en la STC 119/2001, de 24 de mayo. Como por contra la tendencia normativa y jurisprudencial europea evidencian, es cada vez más estrecha la relación entre la protección de los derechos fundamentales y la protección ambiental con la emergencia de la salud como necesidad humana fundamental a considerar preeminentemente en tanto que manifestación íntima de la vida privada y como vertiente del bienestar general de la persona. En el voto particular concurrente del Magistrado Jiménez de Parga a la STC 119/2001, de 24 de mayo se apuntan las claves para dar ese salto que a nuestro juicio se representa como necesario para posibilitar la relación asociativa de la salud con la integridad física de las personas y poder hablar así abiertamente del derecho a la integridad física en un estado completo de salud. El exigente umbral establecido por el TC, y con él por el TS, conforme al cual la lesión del derecho fundamental requiere que el ruido sea de un nivel intenso que ponga en grave e inmediato peligro la salud de las personas se nos antoja demasiado elevado dadas las situaciones de aparente desprotección que se generan cuando no se alcanza esa cota de gravedad e intensidad y no obstante el ruido genera efectos nocivos más que evidentes ${ }^{84}$ que sitúan a los individuos que lo padecen en una suerte de feras non culpes, quod mutare non potest.

Concluimos por ello, haciendo nuestro ahora el interrogante planteado por los Jueces Costa, Ress, Türmen, Zupancik y Steiner en el voto particular disidente formulado a la Sentencia del TEDH de 8 de julio de 2003 (TEDH 2003/40) cuando, encumbrando a la salud como "estado de completo bienestar físico mental y social", lamentan que la Gran Sala del TEDH no reconociera la violación del artículo $8 \mathrm{CEDH}$. En definitiva, y "después de todo ¿qué representan los derechos humanos relativos al respeto del domicilio si, como en este caso, el domicilio de una persona, tanto de día como de noche, resuena constantemente o intermitentemente con el estruendo de los motores de los aviones?".

examen de aquéllas resulta ineludible en el procedimiento especial tendente a la protección de estos. Sin embargo, cuando no existe tal implicación de las cuestiones de legalidad ordinaria su examen en el proceso especial de protección de los derechos fundamentales resulta no sólo innecesario sino también improcedente".

84 El TS, en el Auto 10 de mayo de 1989 (RJ 1989/3867), reconoce que "la contaminación acústica no sólo es que impide el descanso a los que habitan en las viviendas cercanas, sino que perjudica la salud de todos los que se ven sometidos a la incidencia de un número excesivo de decibelios". 
TrTLE: The discipline of the air traffic as for noise (Commentary to the Judgment of the Supreme Court dated 13 th October 2008).

ABSTRACT: The author analyses in this paper the incident that the noise generated by the air traffic presents on the fundamental rights to the life and to the physical integrity, as well as to the domiciliary and personal intimacy from the Judgment of October 13, 2008 dictated by High Court. In this Judgment the keys are demonstrated, on the one hand, to recognize the threshold of bearable noise which overcoming determines the violation of the right to the physical integrity, and on the other hand, the consolidation of the right to the respect to the private and family life opposite to the noise emissions from aircraft suffered by the inbabitants of the surrounding areas of the airport facilities in line with the jurisprudence of the European Court of Human rights.

RESUMEN: El autor analiza en el presente trabajo la incidencia que el ruido generado por el tráfico aéreo presenta sobre los derechos fundamentales a la vida y a la integridad física, así como a la intimidad domiciliaria y personal a partir de la Sentencia de 13 de octubre de 2008 del Tribunal Supremo. En este fallo se evidencian las claves para, por un lado, reconocer el umbral de ruido soportable cuya superación determina la vulneración del derecho a la integridad física y, por otra parte, la consolidación del derecho al respeto a la vida privada y familiar frente a las emisiones sonoras de las aeronaves padecidas por los habitantes de las inmediaciones de las instalaciones aeroportuarias en línea con la jurisprudencia del Tribunal Europeo de Derechos Humanos.

KEY WORDS: Air traffic. Noise emissions from aircraft. Landing in airports. Protection of fundamental rights.

Palabras clave: Tráfico aéreo. Emisiones sonoras de aeronaves. Aterrizaje en aeropuertos. Protección de derechos fundamentales. 